\title{
Synthesis and Characterization of silver nanoparticles using Lablab purpureus flowers (Purple colour) and its anti-microbial activities
}

\author{
N.Muruganantham ${ }^{1}$, R.Govindharaju ${ }^{2}$, P.Anitha ${ }^{3}$ and V. Anusuya ${ }^{4}$ \\ ${ }^{1,2,4}$ PG \& Research Department of Chemistry, Thanthai Hans Roever College (Autonomous), Perambalur \\ ${ }^{3}$ Department of Physics, Roever College Of Engineering and Technology, Perambalur \\ *Corresponding author: nmuruganchem@gmail.com
}

Available online at: www.isroset.org

Received: 05/Dec/2018, Accepted: 22/Dec/2018, Online: 31/Dec/2018

\begin{abstract}
In recent years, green Bio-synthesis of silver nanoparticles (AgNPs) has gained much interest from chemists and researchers. In this concern, Indian flora has yet to divulge innumerable sources of cost-effective, non -hazardous, reducing and stabilizing compounds utilized in preparing AgNPs. This study investigates an effective and sustainable route of AgNP preparation from $1 \mathrm{mM}$ aqueous $\mathrm{AgNO}_{3}$ using extracts of Lablab purpureus flowers (purple colour) which are well adorned for their wide availability and medicinal property. The AgNPs were characterized by UV-visible (vis) spectrophotometer, Scanning electron microscopy (SEM), Fourier transform infrared spectrometer (FTIR) analysis, and XRD. The AgNPs obtained from extracts significantly higher antimicrobial activities against staphylococcus aureus and E.Coli.in comparison to both $\mathrm{AgNO}_{3}$ and raw plant extracts. In totality, the AgNPs prepared are safe to be discharged in the environment and possibly utilized in process of pollution remediation. AgNPs may also be efficiently utilized in green research to obtain better health using crop plants as shown by our study.
\end{abstract}

Keywords: Green synthesis, Lablab purpureus, Silver nanoparticles, SEM, Antimicrobial property; etc.,

\section{INTRODUCTION}

The field of Nanoscience has blossomed over the last twenty years and the need for nanotechnology will only increase, as miniaturization becomes more important in areas such as computing, sensors, and biomedical applications. Advances in this field largely depend on the ability to synthesize nanoparticles of various nanomaterials, based on their sizes, shapes, as well as their efficiency to assemble them into complex architectures. Nanotechnology provides the ability to engineer the properties of materials by controlling their size and this has driven research towards a multitude of potential uses for Nanomaterial. Phyllanthus acidus Skeels, an important medicinal plant belonging to the genus Phyllanthus (Euphorbiaceae), is widely cultivated in worldwide and its extracts have been used for treating alcoholism. Phyllanthus acidus known as the Otaheite gooseberry, Malay gooseberry, Tahitian gooseberry, country gooseberry, star gooseberry, starberry, West India gooseberry, damsel, grosella (in Puerto Rico), jimbilin (in Jamaica), damsel (in Grenada), karamay (in the Northern Philippines), cermai (in Indonesia and Malaysia), Goanbili (in Maldives) or simply gooseberry tree, is one of the trees with edible small yellow berries fruit in the Phyllanthaceae family. Despite its name, the plant does not resemble the gooseberry, except for the acidity of its fruits. It is mostly cultivated for ornamentation. The medicinal activities of
Phyllanthus species are antipyretic, analgesic, antiinflammatory, anti-hepatotoxic and antiviral [1-4]. Fruits of the two well-known species, $P$. acidus $L$. and P. emblica $L$. contain high contents of vitamin $\mathrm{C}$ and have been used for used for improving eyesight and memory. It prevents action against Diabetes and reliefs from cough [5]. Another species of the family, $P$. amarusis an important herbal medicine due to its effective antiviral activities especially towards the hepatitis B virus[6-8].Traditionally, P.acidus has been used in the treatment of several ailments including inflammatory and oxidative stress-related disorders such as gastric trouble (Jules and Paull,2008) [9].

Green Synthesis and characterization of nanoparticles is under exploration due to its wide medical applications and various research interests in nanotechnology. In the current study, the plant extract of Persea Americana (Avocado) (Family-Lauraceae) is used for the synthesis of silver nanoparticles (AgNPs). This study investigates an efficient and sustainable route of AgNPs preparation from $1 \mathrm{mM}$ aqueous $\mathrm{AgNO}_{3}$ using leaf extracts. The complete reduction of silver ions was observed after $12 \mathrm{hrs}$ of reaction at $40^{\circ} \mathrm{C}$ under shaking condition. The colour changes in reaction mixture (pale yellow to dark brown colour) was observed during the incubation period, because of the formation of silver nanoparticles (AgNPs) in the reaction mixture enables to produce particular colour due to their specific properties 
(Surface Plasmon Resonance). The formation of silver nanoparticles was confirmed by UV-Visible spectroscopy, Fourier Transform Infra-Red (FT-IR) spectroscopy analysis, X-Ray Diffraction (XRD) pattern, Transmission electron microscopy (TEM). The results showed that the leaf extract is optimum for the synthesis of silver nanoparticles and it is also known to have the ability to inhibit the growth of various pathogenic microorganisms. The average size of synthesized silver nanoparticles is found to be $27.42 \mathrm{~nm}$ using XRD data by Scherrer's formula, which is approximately similar as the size obtained in TEM Analysis $(27.58 \mathrm{~nm})$. In total, the AgNPs prepared are safe to be discharged in the environment and possibly utilized in processes of pollution remediation. AgNPs may also be efficiently utilized in anti-inflammatory activity of Pharmaceutical research to obtain better result of plant as shown by our study [10].

Nanoparticles are being viewed as fundamental building blocks of nanotechnology. An important aspect of nanotechnology concerns the development of experimental processes for the synthesis of nanoparticles of different sizes, shape and controlled dispersity. With the development of new chemical or physical methods, the concern for environmental contaminations are also heightened as the chemical procedures involved in the synthesis of nanoparticles generates a large amount of hazardous byproducts. Thus, there is a need for green method that includes a clean, non-toxic and environment friendly method of nanoparticles synthesis [11]. As a result, researchers in the field of nanoparticles synthesis and assembly have turned to biological system of inspiration. Biosynthetic processes for nanoparticles would be more useful if nanoparticles were produced extra celluarly using plants or their extracts in a controlled manner according to their size, shape and dispersity [12]. The aqueous silver nitrate solution, after reacting with geranium leaf extract, led to rapid formation of highly stable, crystalline silver nanoparticles (16 to $40 \mathrm{~nm}$ ) [13]. Various approaches available for the synthesis of silver NPs include chemical [14], electrochemical [14], radiation[15], photochemical methods [16] and Langmuir-Blodget [17] and biological techniques [18].

The uses of engineered nanomaterials have increased as a result of their positive impact on many sectors of the economy including agriculture. In the current study, the plant extract of Citrullus Lanatus is used for the synthesis of silver nanoparticles. The plant extract is mixed with $\mathrm{AgNO} 3$, and then it is incubated. The extract is kept in microwave oven for exposure of heat, then it is dried and powdered. The synthesized dried powder is confirmed as nanoparticles by colour transformation. The characterization of silver nanoparticles was studied by UV-Vis spectroscopy,
FTIR, XRD\& TEM. The silver nanoparticles synthesized were generally found to be in the size ranging from 1-100 $\mathrm{nm}$. The average size of synthesized silver nanoparticles is found to be $15.98 \mathrm{~nm}$ using XRD data by Scherrer's formula, which is approximately similar as the size obtained in TEM Analysis $16.32 \mathrm{~nm}$. In totality, the AgNPs prepared are safe to be discharged in the environment and possibly utilized in processes of pollution remediation. AgNPs may also be efficiently utilized in Anti-inflammatory activity of Pharmaceutical research to obtain better result of plant as shown by our study. The Anti-inflammatory activity of silver nanoparticles was tested on human blood cells which confirms that the plant mediated synthesis of silver nanoparticles have a significant Anti-inflammatory effect on human blood cells [19]. In the present work, the synthesis of silver nanoparticles from aqueous solution of silver nitrate using Lablab purpureus flowers (purple colour). Further silver nanoparticles were characterized by using UV-visible (vis) spectrophotometer, Scanning electron microscopy (SEM), Fourier transform infrared spectrometer (FTIR) and anti-microbial activities.

\section{MATERIALS AND METHODS}

\section{PREPARATION OF FLOWER EXTRACT}

The fresh flowers of Lablab purpureus flowers (purple colour) was collected and washed thoroughly with sterile double distilled water (DDW). Twenty gram of sterilized flower samples were taken and cut into small pieces. Finely cut leaves were placed in a $500 \mathrm{ml}$ Erlenmeyer flask containing $100 \mathrm{ml}$ of sterile DDW After that, the mixture was boiled for 5 minutes and then filtered. The extract was stored in $4^{0} \mathrm{C}$.

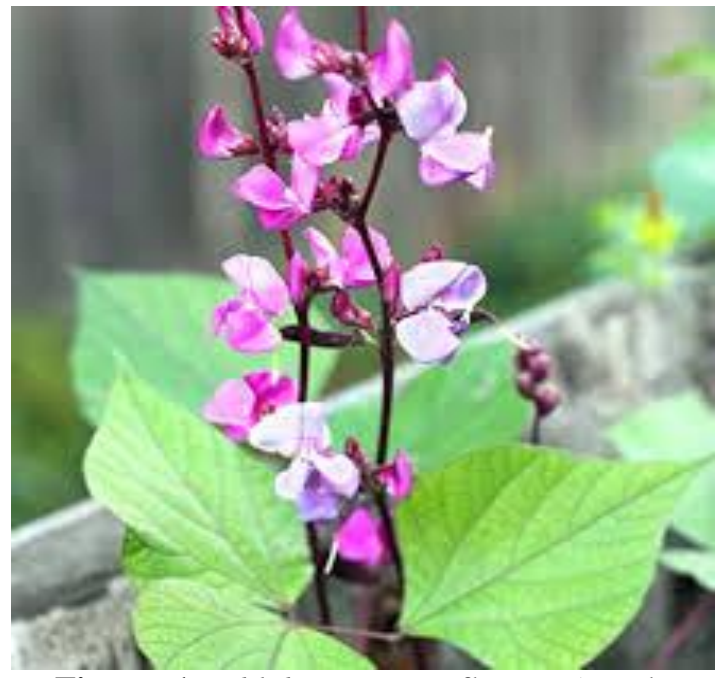

Figure: 1 Lablab purpureus flowers (purple colour) 


\section{SYNTHESIS OF SILVER NANOPARTICLES}

Silver nitrate was used as precursor in the synthesis of silver nanoparticles. $100 \mathrm{ml}$ flower extract was added to $100 \mathrm{ml}$ of $0.1 \mathrm{~N} \mathrm{AgNO}_{3}$ aqueous solution in conical flask of $250 \mathrm{ml}$ content at room temperature. The flask was thereafter put into shaker $(100 \mathrm{rpm})$ at $500{ }^{\circ} \mathrm{C}$ and reaction was carried out for a period of $12 \mathrm{hrs}$. Then the mixture (Flower extracts \& Silver nitrate solution) is kept in microwave oven for exposure of heat. Finally, the mixture was completely dried after a period of 20 minutes and hence Nanoparticles in form of powders were obtained.

\section{UV VISIBLE SPECTROSCOPY ANALYSIS}

The colour change in reaction mixture (metal ion solution + flower extract) was recorded through visual observation. The bio reduction of silver ions in aqueous solution was monitored by periodic sampling of solid and subsequently measuring UV visible spectra of the solid sample. UVvisible spectra of sample were monitored as a function of time of reaction on the UV-visible spectroscopy and the investigation was carried out using PERKIN ELMER (Lambda 35 model) spectrometer in the range of $190 \mathrm{~nm}$ to $1100 \mathrm{~nm}$.

\section{FT-IR MEASURMENT}

The Fourier transform infrared (FTIR) investigation is carried out using PERKIN ELMER (Spectrum RXI) spectrometer in the range of $400 \mathrm{~cm}-1$ to $4000 \mathrm{~cm}-1$. The functional groups were identified using the peak assignments.

\section{XRD MEASURMEND}

The sample was drop- coated onto Nickel plate by just dropping a small amount of sample on the plate frequently, allowed to dry and finally thick coat of sample was prepared. The particle size and nature of the silver nanoparticle was determined using $\mathrm{X}$-ray diffraction (XRD). This was carried out using Rigaku miniflex-3 model with $30 \mathrm{kv}, 30 \mathrm{~mA}$ with $\mathrm{Cuk} \alpha$ radians at $2 \theta$ angle.

\section{SEM ANALYSIS}

Sample is dispersed with acetone and exposed in ultrasonics for 5 minutes. Take a drop of a solution from the sample and drop it on the grid, leave until it dries. After drying the sample is inserted into SEM instruments using model is Tecnai T20 Making in FEI, Netherlands operating at $200 \mathrm{KeV}$ Tungsten Filament.

\section{ANTIBACTERIAL ACTIVITY}

Micro - organisms and culture media

Bacterial cultures such as, Staphylococcus aureus, E.coli, were obtained from Eumic analytical Lab and Research Institute, Tiruchirappalli. Bacterial strains were maintained on Nutrient agar slants (Hi media) at $4^{\circ} \mathrm{C}$.

\section{Inoculum preparation}

Bacterial cultures were subcultured in liquid medium (Nutrient broth) at $37^{\circ} \mathrm{C}$ for $8 \mathrm{hrs}$ and further used for the test $\left(10^{5}-10^{6} \mathrm{CFU} / \mathrm{ml}\right)$. These suspensions were prepared immediately before the test was carried out.

\section{Preparation of culture media Nutrient agar medium}

Nutrient agar medium is one of the most commonly used medium for several routine bacteriological purposes:

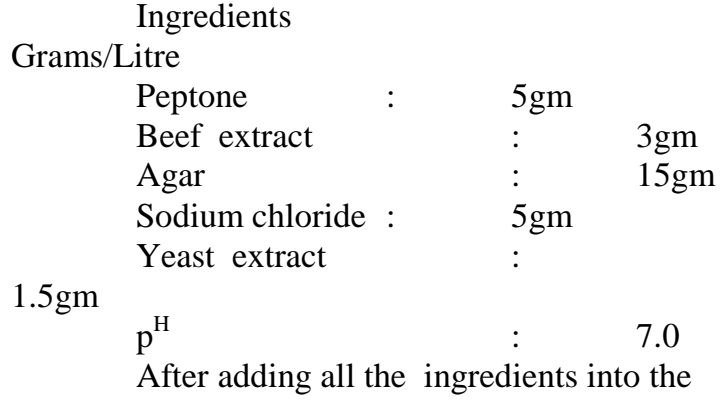
distilled water it is boiled to dissolve the medium completely and sterilized by autoclaving at $15 \mathrm{Ib}$ psi pressure $\left(121^{\circ} \mathrm{C}\right)$ for 15 minutes.

\section{Nutrient broth}

The nutrient broth was prepared by the same composition without agar. After adding all the ingredients into the distilled water it is boiled to dissolve in the medium completely and it is sterilized by autoclaving at $15 \mathrm{ib}$ psi pressure $\left(121^{\circ} \mathrm{C}\right)$ for 15 minutes.

\section{Preparation of plant material}

Flowers of the plant materials taken for this study were shade dried individually at room temperature and then powdered by using electric blender. About $10 \mathrm{gm}$ of fresh plant materials (flower) were extracted with $100 \mathrm{ml}$ of distilled water 91:10. They were kept for seven days at room temperature $\left(31^{\circ} \mathrm{C}\right)$ for complete extraction. After seven days. The extracts were filtered through what man no.1 filter paper. This extract was collected in beaker and kept in refrigerator.

\section{Continuous hot extraction using soxhlet apparatus}

In concentrated preparation, there is first extraction followed by evaporation. In continuous the operations i.e., extraction and evaporation are combined in the apparatus were used for this purpose. To execute continuous extraction a soxhlet apparatus is uses soxhlet continuous extractor. The apparatus is used for the extraction on coarse drug powder placed in a thimble made of filter paper is inserted into the wide tube of the extractor. The solvent which is taken in the flask is heated, the vapours arise from the solvent get into the condenser through a side tube and the liquid condensed from the vapours drips into the thimble. The solvent liquid level slowly rises and during 
this period the dried flower materials gets extracted of its soluble constituents. When the level of the liquid reaches the top of the siphon it gets siphoned into flask. The suction effect of the siphoning assists permeation of the solvent through the drug.

Again a portion of the solvent from the solution vapourised leaving the constituents in the flask itself and the process mentioned above is repeated. The same process is repeated again and again until all the solutes are extracted. This kind of continuous not percolation (soxhlation) is undertaken when the active constituents are not readily soluble in the cold and are thermo labile e.g., grainder Oleoresin is extracted with ethanol.

\section{Assay of antimicrobial activity}

\section{Microbial inoculum preparation}

The nutrient broth were prepared, then identified bacterial colonies were inoculated into the broth culture were used for antimicrobial activity.

\section{Kirby bauer agar well diffusion assay}

The nutrient agar medium was prepared and sterilized by autoclaving at $121^{\circ} \mathrm{C} 15 \mathrm{lbs}$ pressure for 15 minutes then aseptically poured the medium into the sterile petriplates and allowed to solidify the Bacterial broth culture was swabbed on each petriplates using a sterile buds. Then wells were made by well cutter. The organic solvent extracts of flower were added to each well aseptically.

This procedure was repeated for each Petri plates then the petriplates were incubated at $37^{\circ} \mathrm{C}$ for $24 \mathrm{hrs}$. After incubation the plates were observed for the zone of inhibition.

\section{RESULT AND DISCUSSION}

\section{UV-Visible Spectroscopy Analysis}

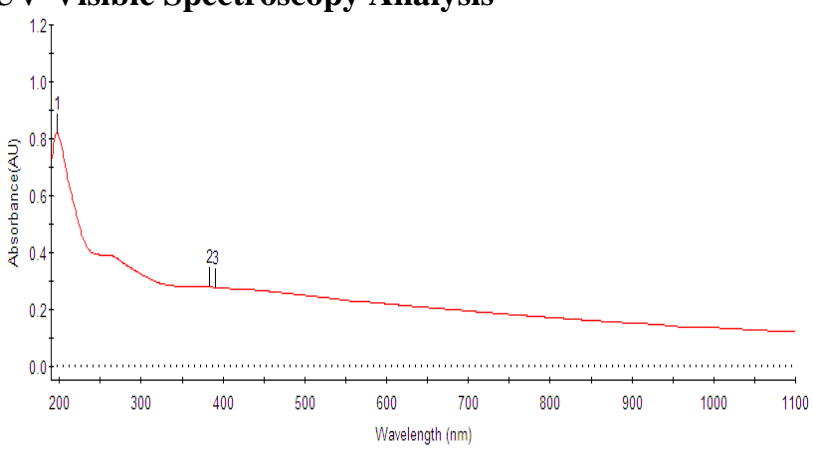

Figure: 2 UV-Visible spectrum of synthesized silver nanoparticles using flower extract of Lablab purpureus (purple colour)

UV-Visible spectroscopy analysis showed the absorbance band of silver nanoparticles synthesized using Lablab purpureus (purple colour) flower extract at 197.10nm,382.60nm, and 391.30nm which confirms the presence of poly-unsaturated and aromatic compound (Isoguinoline) (Advanced strategies in food analysis, UVVIS spectrometry International Journal of medicine and Pharmaceutical Research by Richart koplik.

\section{FT-IR measurment}

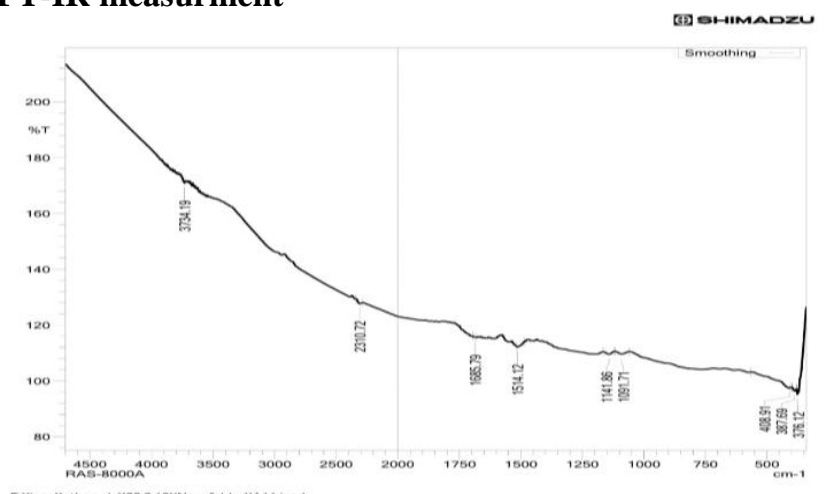

Figure : 3 FT-IR Spectrum of synthesized silver nanoparticles using flower extract of Lablab purpureus (purple colour)

The lablab purpureous (purple colour) related functional groups were identified using the peak assignments. A medium peak at $3734.19 \mathrm{~cm}^{-1}$ was assigned to the $\mathrm{N}-\mathrm{H}$ stretching in amide group, multible brode peak at 2310.72 $\mathrm{cm}^{-1}$ was assigned to $\mathrm{N}-\mathrm{H}$ stretching primary ammonium ions group, similar conjugated effets at $1685.79 \mathrm{~cm}^{-1}$ was assigned to $\mathrm{C}=\mathrm{O}$ Stretching anhydride group, a strong peak at $1514.12 \mathrm{~cm}^{-1}$ was assigned to $\mathrm{N}-\mathrm{O}$ stretching Nitro compound group, a strong peak at $1141.86 \mathrm{~cm}^{-1}$ was assigned to $\mathrm{P}-\mathrm{O}$ stretching Phosporus oxide, strong peck at $1091.71 \mathrm{~cm}^{-1}$ was assigned to $\mathrm{C}-\mathrm{O}$ stretching Alkyl aryl ether medium are observed.

\section{XRD measuremt}

Gauss value:

According to Gauss formula,

$$
\varnothing=\mathrm{Q} / €
$$

Partical size $D=14.9143 \mathrm{~nm}$

Surface area $\mathrm{S}=59.2920 \mathrm{~m}^{2} / \mathrm{g}$

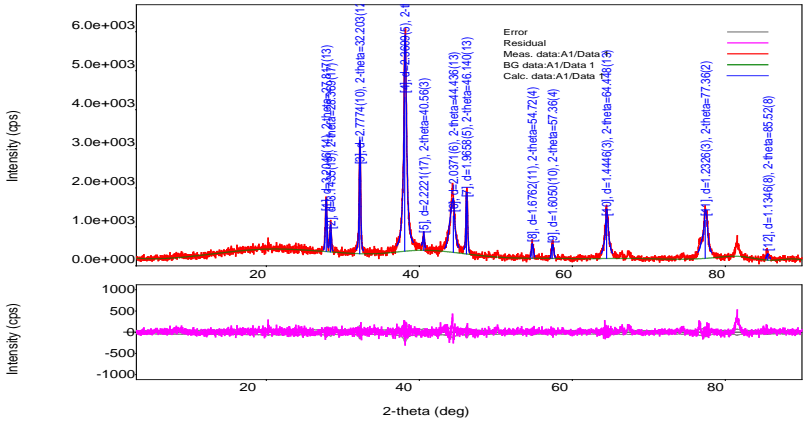

Figure: 4 XRD Spectrum of synthesized silver nanoparticles using flower extract of Lablab purpureus (purple colour) 


\section{SEM ANALYSIS}
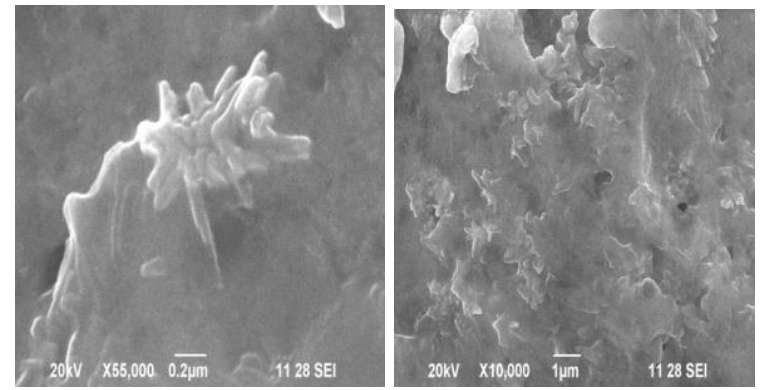

Figure: 5 SEM image of synthesized silver nanoparticles using flower extract of Lablab purpureus

(purple colour)

SEM analysis shows uniformly distributed silver nanoparticles on the surfaces of the cells. SEM analysis reveals individual spherical polydispersed AgNPs as well as number of aggregates, which wear irregular in shape. The size of the silver nanoparticles was found to be 5$50 \mathrm{~nm}$, with an average size $14.91 \mathrm{~nm}$. The larger silver particles may be due to the aggregation of the smaller ones.

\section{Anti-microbial activity}

In the present study, flowers of Lablab purpureus (purple colour) exhibited significant anti- microbial activity when compared with standard drug. It is evident from the data presented in table 1 that the sample possesses antibacterial activity. The disc diffusion method result showed the zone of inhibition for $25 \mathrm{mg} / \mathrm{ml}$ as $15 \mathrm{~mm}$, and $15 \mathrm{~mm}$, for $50 \mathrm{mg} / \mathrm{ml}$ showing $18 \mathrm{~mm}$ and $17 \mathrm{~mm}$ $75 \mathrm{mg} / \mathrm{ml}$ showed $20 \mathrm{~mm}$ and $19 \mathrm{~mm}$ for $100 \mathrm{mg} / \mathrm{ml}$ as $24 \mathrm{~mm}$, and $22 \mathrm{~mm}$, against staphylococcus aureus ,E.coli respectively when compared with standard drug Gentamicin showing $22 \mathrm{~mm}$, and $23 \mathrm{~mm}$ zone of inhibition respectively. Then it is evident from the data presented in table 1 that the sample possesses antibacterial activity. The above result shows that the activity of the compound of Lablab purpureus flower (purple colour) shows significant antibacterial activities.

Table1: Anti-bacterial activity of synthesized silver nanoparticles using flower extract of Lablab purpureus (purple colour)

\begin{tabular}{|c|c|c|c|c|c|}
\hline \multirow{2}{*}{ SAMPLE } & \multicolumn{5}{|c|}{$\begin{array}{c}\text { Extract 100 } \boldsymbol{\mu l} \text { added and Zone of } \\
\text { inhibition }(\mathbf{m m} / \mathbf{m l})\end{array}$} \\
\cline { 2 - 6 } & $\mathbf{2 5} \boldsymbol{\mu \mathbf { l }}$ & $\begin{array}{c}\mathbf{5 0} \\
\boldsymbol{\mu l}\end{array}$ & $\mathbf{7 5} \boldsymbol{\mu l}$ & $\begin{array}{c}\mathbf{1 0 0} \\
\boldsymbol{\mu l}\end{array}$ & Control \\
\hline $\begin{array}{c}\text { Staphylococcus } \\
\text { aureus }\end{array}$ & 15 & 18 & 20 & 24 & 22 \\
\hline E.coli & 15 & 17 & 19 & 22 & 23 \\
\hline
\end{tabular}

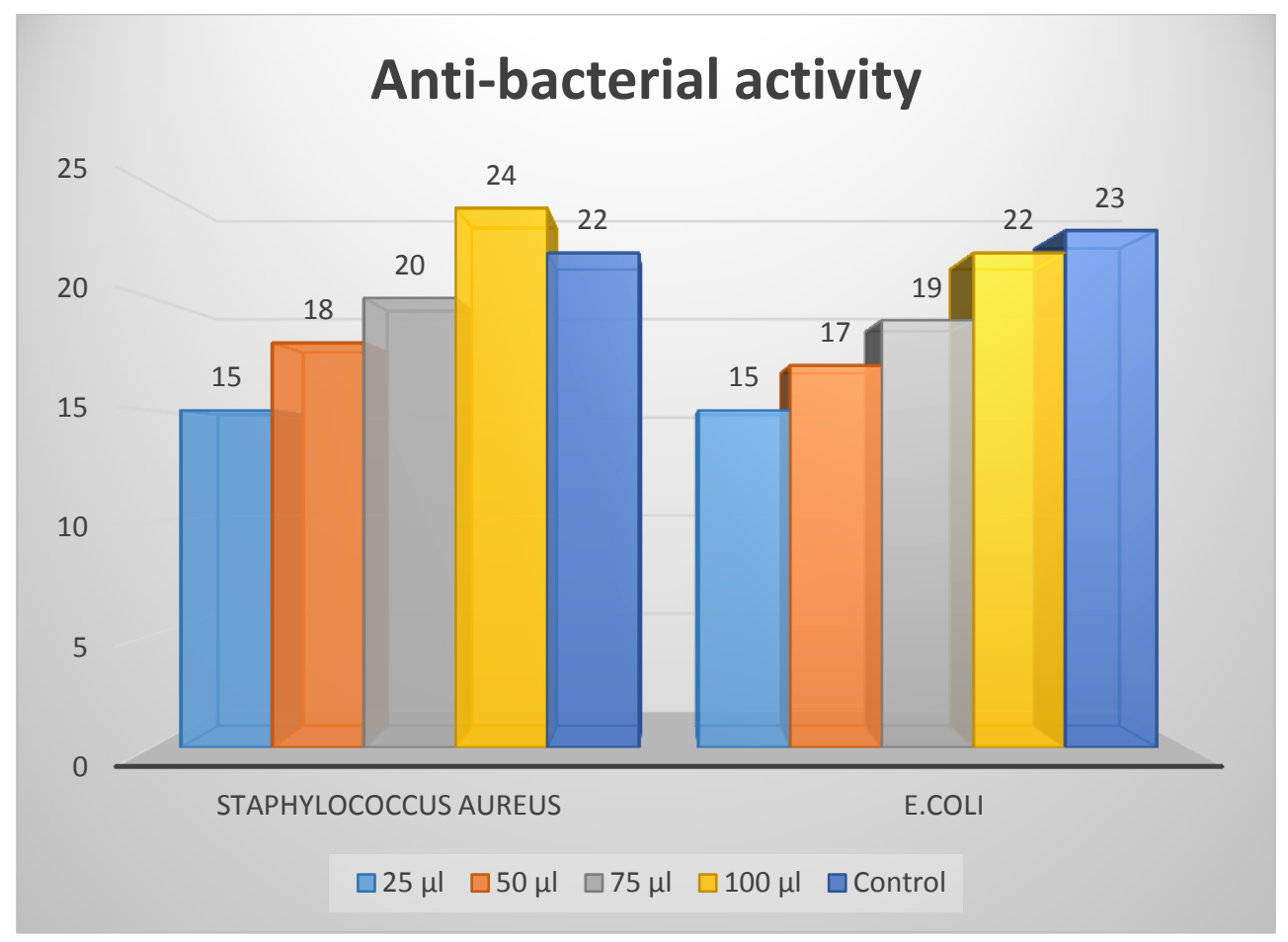

Figure: 6 Graphical representation Anti-bacterial activity of synthesized silver nanoparticles using flower extract of Lablab purpureus (purple colour) (standard: Gentamicin, concentration 1mg/ml) 


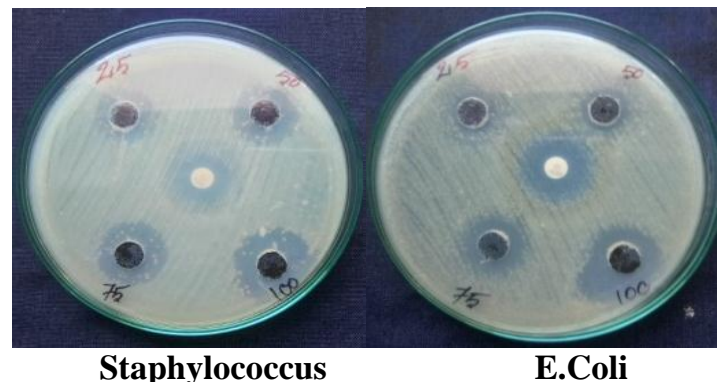

Figure: 7 Image of Anti-bacterial activities of synthesized silver nanoparticles using flower extract of

Lablab purpureus (purple colour) (standard: Gentamicin, concentration $1 \mathrm{mg} / \mathrm{ml}$ )

\section{CONCLUSION}

The present study reports the facile approach of biosynthesizing $\mathrm{AgNPs}$ from $\mathrm{AgNO}_{3}$ using the aqueous extract of Lablab purpureus (purple colour) flower. The adopted method is well suited with green chemistry principles as the plant extract serves as a dual functional molecule as reductant and a stabilizing agent for the synthesis of AgNPs. The efficiency and the influence of various process variables in the biosynthesis of AgNPs analysed include reductant concentration, temperature and time. The interesting conclusion arrived from the study is that the shape and size of the nanoparticles synthesized have the direct and strong influence and dependent on process variables used in the experiment. The UV-visible spectra confirmed the reduction of silver ions at $391.30 \mathrm{~nm}$. XRD analysis confirmed the crystalline structure of AgNPs. From FTIR and XRD analyses it was observed that Lablab purpureus (purple colour) flower extract acted as apparent stabilizer for the synthesis of AgNPs. The size and morphology of particles were characterized using SEM and the images showed the AgNPs in the average range from 14$50 \mathrm{~nm}$ and Surface area $\mathrm{S}=59.2920 \mathrm{~m}^{2} / \mathrm{g}$. Further, the biosynthesized AgNPs showed significant antibacterial action on tested pathogenic microorganisms. As a result it is observed that a fine tuning of process variables may give the end product with typical physical characteristics.

\section{REFERENCES}

[1]. Zhang YJ, Nagao T, Tanaka T, Yang CR, Okabe H, Kouno I.. Anti-proliferative activity of the main constituents from Phyllanthus emblica. Biol Pharm Bull., 27,pp- 251-255, 2004.

[2]. Sousa M, Ousingsawat J, Seitz R, Puntheeranurak S, Regalado A, Schmidt A, et al. An extract from the medicinal plant Phyllanthus acidus, Iisolated compounds induce airway chloride secretion: a potential treatment for cystic fibrosis. MolPharmacol., 71,pp-36676, 2007.

[3]. Unander DW, Webster DW, Blumberg BS. Record of usage or assays in Phyllanthus (Euphorbiaceae) I. Subgenera Isocladus,
Kirganelia, Cicca and Emblica. J Ethnopharmacol., 30, pp-23364,1990 .

[4]. Unander DW, Webster DW, Blumberg BS. Uses and bioassays in Phyllanthus (Euphorbiaceae): acompilation II. The subgenus Phyllanthus. J Ethnopharmacol., 34,pp-97-133, 1991;.

[5]. Ott M, Thyagarajan SP, Gupta S. Phyllanthusamarus suppresses hepatitis B virus by interrupting interactions between HBV enhancer I and cellular transcription factors. Eur J Clin Invest., 27,pp-908-15, 1997.

[6]. Rai V, Khatoon S, Bisht SS, Mehrotra S. Effect of cadmium on growth, ultramorphology of leaf and secondary metabolites of Phyllanthusamarus Schum and Thonn. Chemosphere,61,pp- 164450, 2005.

[7]. Jules, Janick, Paull, Robert E. The Encyclopedia Q5 of Fruit \& Nuts.CABI Publishing pp-373, 2008.

[8]. P.Anitha, P.Sakthivel, Synthesis and Characterization of Silver Nanoparticles Using Persea americana (Avocado) and its Antiinflammatory Effects on Human Blood Cells, Int. J. Pharm. Sci. Rev. Res., 35(2),pp-173-177, 2015.

[9]. Mukherjee, A. Ahmad, D. Mandal, S. Senapati, S.R. Sainkar, M.I. Khan, R. Parishcha, P.V. Ajaykumar, M. Alam, R. Kumar, M. Sastry, Fungus-Mediated Synthesis of Silver Nanoparticles and Their Immobilization in the Mycelial Matrix: A Novel Biological Approach to Nanoparticle Synthesis, Nano Letters, 1(10), pp-515519, 2001.

[10]. K.Simkiss, K.M. Wilbur, "Biomineralization," Cell Biology and Mineral Deposition, Academic Press New York (1989).

[11]. V. Kumar, S.K. Yadav, J. Chem. Technol., Syzygium cumini leaf and seed extract mediated biosynthesis of silver nanoparticles and their characterization, 85(10),pp-1299-1422, 2001.

[12]. S.S. Shankar, A. Ahmad, R. Pasricha, M. Sastry, Bioreduction of chloroaurate ions by geranium leaves and its endophytic fungus yields gold nanoparticles of different shapes J. Mater. Chem., 13, pp-1822-1826, 2003.

[13]. Sun Y, Yin Y, Mayers BT, Herricks T, Xia Y, Uniform form silver nanowires synthesis by reducing $\mathrm{AgNO}_{3}$ with ethylene glycol in presence of seeds and poly(vinyl pyrrolidone). Chem Mater, 14, pp-4736-4745, 2002.

[14]. Yin B, Ma H, Wang S, Chen S, Electrochemical synthesis of silver nanoparticles under protection of poly (Nvinylpyrrolidone). J PhysChem B, 107, pp-8898-8904, 2003.

[15]. Dimitrijevic NM, Bartels DM, Jonah CD, Takahashi K, Rajh T, Radiolytically induced formation and optical absorption spectra of colloidal silver nanoparticles in supercritical ethane. J PhysChem B, 105,pp-954-959, 2001.

[16]. Callegari A, Tonti D, Chergui M. Photochemically grown silver nanoparticles with wavelength-controlled size and shape. Nano Lett, 3, pp-1565-1568, 2003.

[17]. Zhang L, Shen YH, Xie AJ, Li SK, Jin BK, Zhang QF, One-step synthesis of monodisperse silver nanoparticles beneath vitamin $\mathrm{E}$ Langmuir monolayers. JPhysChem, B 110, pp-6615-6620, 2006.

[18]. Swami A, Selvakannan PR, Pasricha R, Sastry M. One-step synthesis of ordered two dimensional assemblies of silver nanoparticles by the spontaneous reduction of silver ions by pentadecylphenol Langmuir monolayers. J PhysChem B, 108,pp19269,2004

[19]. P. Anitha, P. Sakthivel, Microwave Assisted Synthesis and Characterization of Silver Nanoparticles Using Citrullus Lanatus Leaf Extract and Its Anti-Inflammatory Activity Against Human Blood Cells, International Journal of Advanced Engineering and $\begin{array}{lll}\text { Nano Technology, } & 3016 .\end{array}$ 


\section{Author's Profile}

Dr.N.Muruganantham is currently working as Assistant Professor, PG \& Research Department of Chemistry, Thanthai Hans Roever College (Autonomous), Perambalur, Tamil Nadu, India. He has awarded with a Ph.D. Degree in Chemistry from Bharathidasan University, Tamil Nadu, India in 2018. The author has published more than 65 research papers in reputed international journals.

Dr.R.Govindharaju is currently working as Assistant Professor, PG \& Research Department of Chemistry, Thanthai Hans Roever College (Autonomous), Perambalur, Tamil Nadu, India. He has awarded with a Ph.D. Degree in Chemistry from Bharathidasan University, Tamil Nadu, India in 2017. The authors have published more than 20 research papers in reputed international journals.

Dr.P.Anitha is currently working as Assistant Professor, Department of Physics, Roever College Of Engineering and Technology, Perambalur, Tamil Nadu, India. she has awarded with a Ph.D. Degree in Physics from Bharathidasan University in 2018, Tamil Nadu, India. The authors have published more than 15 research papers in reputed international journals.

V. Anusuya is a Research scholar, PG \& Research Department of Chemistry, Thanthai Hans Roever College (Autonomous), Perambalur, Tamil Nadu, India. She has completed M.Sc.,M.Phil. Degree in Chemistry from Bharathidasan University, Tamil Nadu, India.
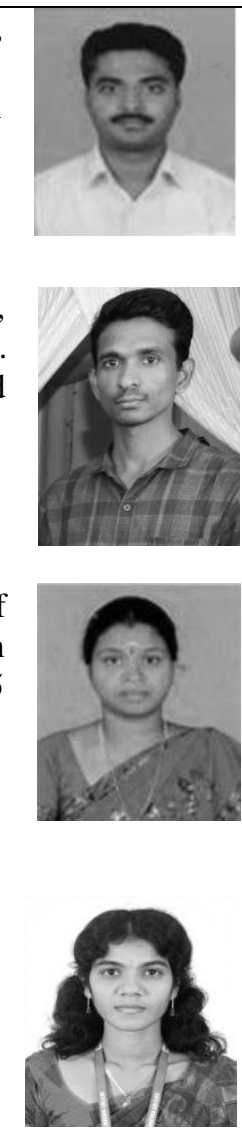